\title{
Preconditioning by hydraulic fracturing - what does it do and what are the issues in modelling it?
}

\author{
T.R. Stacey University of the Witwatersrand, South Africa
}

\begin{abstract}
Preconditioning by means of hydraulic fracturing is being used increasingly in deep block caves and has shown significant benefits. However, what does the hydraulic fracturing do to the rock mass? Does it change the stiffness and strength in a confined situation? How does it achieve the observed benefits, and how can the effects be modelled? Simple laboratory tests are described that demonstrate that, under confined conditions, fractures in the rock do not reduce the stiffness or strength of the rock. Mining involves unloading of the rock mass, and under these unloading conditions, associated with the induced and natural fractures, directionality of deformability and strength will result. Thus modelling of a hydraulically fractured rock mass is not trivial and the directionality, as well as alternative criteria for fracture and failure of the rock and rock mass, must be taken into account. Possible explanations of the benefits experienced after preconditioning are given.
\end{abstract}

\section{Introduction}

As caving mines have progressed to greater depths, with orebodies located in hard, unweathered rock subjected to high stresses, several mining problems have developed. Two of these are:

- an increase in seismicity, often resulting in rockbursts, which are a safety hazard and can cause major damage to mining infrastructure, resulting in negative impacts on mine productivity and hence profitability

- a decrease in cavability, with the consequence that initiation of caving is delayed, and production build-up is slower, with negative economic consequences.

In an attempt to combat these problems, preconditioning of the rock mass using hydraulic fracturing is being practised increasingly. Preconditioning has been shown to be of benefit to caving: Araneda and Sougarret (2007) state that preconditioning by hydraulic fracturing in the Diablo Regimiento Sector of El Teniente Mine resulted in breakthrough after an undercutting period of 10 months compared with the predicted period of 23 months without preconditioning. This facilitated an increase in production compared with the production profile of the original plan. In addition, these authors found that the seismicity in Diablo Regimiento after preconditioning was much smaller in magnitude (Richter 1.2) than before preconditioning (Richter 2), and no rockbursts were experienced.

From the experiences of mines on which preconditioning has been implemented, there is no doubt that it has had beneficial effects. However, the philosophical question that arises is, "What does hydraulic fracturing do to the rock mass, and how can this be modelled to improve analysis and planning in the future?"

\section{The products of hydraulic fracturing}

Hydraulic fracturing involves the injection of water at high pressure in purpose-drilled boreholes at closely spaced intervals down the length of the borehole. The result is the creation of fractures in planes normal to the minimum principal stress. These fractures can be extensive, with radii in excess of $40 \mathrm{~m}$ having been measured (Van As and Jeffrey, 2004). Once the injection pressure is reduced, the fracture closes and water will only be injected again when the fracture opening pressure is again reached. The set of fractures induced in a preconditioning programme can be considered to decrease the joint spacing of a joint set that is subparallel to the fracture orientations, or to create a new joint set if the fracture orientations are not sub-parallel to any existing set. Before the fracturing the rock mass was in a confined state, and after the fracturing it is again confined by the same in situ stress field. Therefore, what effect has the fracturing had on the 
'constitution' of the rock mass that might change its behavioural character? Has it changed the stiffness? Has it changed the strength? In an attempt to contribute to the answering of these questions, some simple laboratory tests were carried out. These are described in the following section.

\section{Laboratory testing of rock cores}

Cores of hard, brittle norite rock were subjected to uniaxial compressive tests, and to triaxial compressive tests in a Hoek cell. Intact cores as well as cores that contained fractures normal to the core axis (horizontal), and cores that contained fractures parallel to the core axis (vertical), were tested under triaxial conditions with confining pressures of 5, 10 and $15 \mathrm{MPa}$. In uniaxial compression, intact cores were tested thoroughly, including the determination of the modulus of elasticity and Poisson's ratio of the norite by means of strain gauges. Failure of the uniaxial specimens occurred with considerable violence, which is common in hard brittle specimens tested in conventional compression testing machines. An additional test of a horizontally fractured specimen was carried out in an attempt to record its failure behaviour visually using a high-speed camera. This was unsuccessful, but the fragmentation of the specimen observed after the failure will be referred to later. The geometries of the pre-fractured specimens are shown in Figure 1. The horizontal "fractures" were formed by cutting the cores with a diamond saw and then polishing the cut surfaces to ensure that there would be no stress concentrations introduced due to surface irregularities. The vertical "fractures" were introduced into blocks of norite by diamond saw cutting. The pieces were then clamped together and the cores drilled parallel to the fractures.
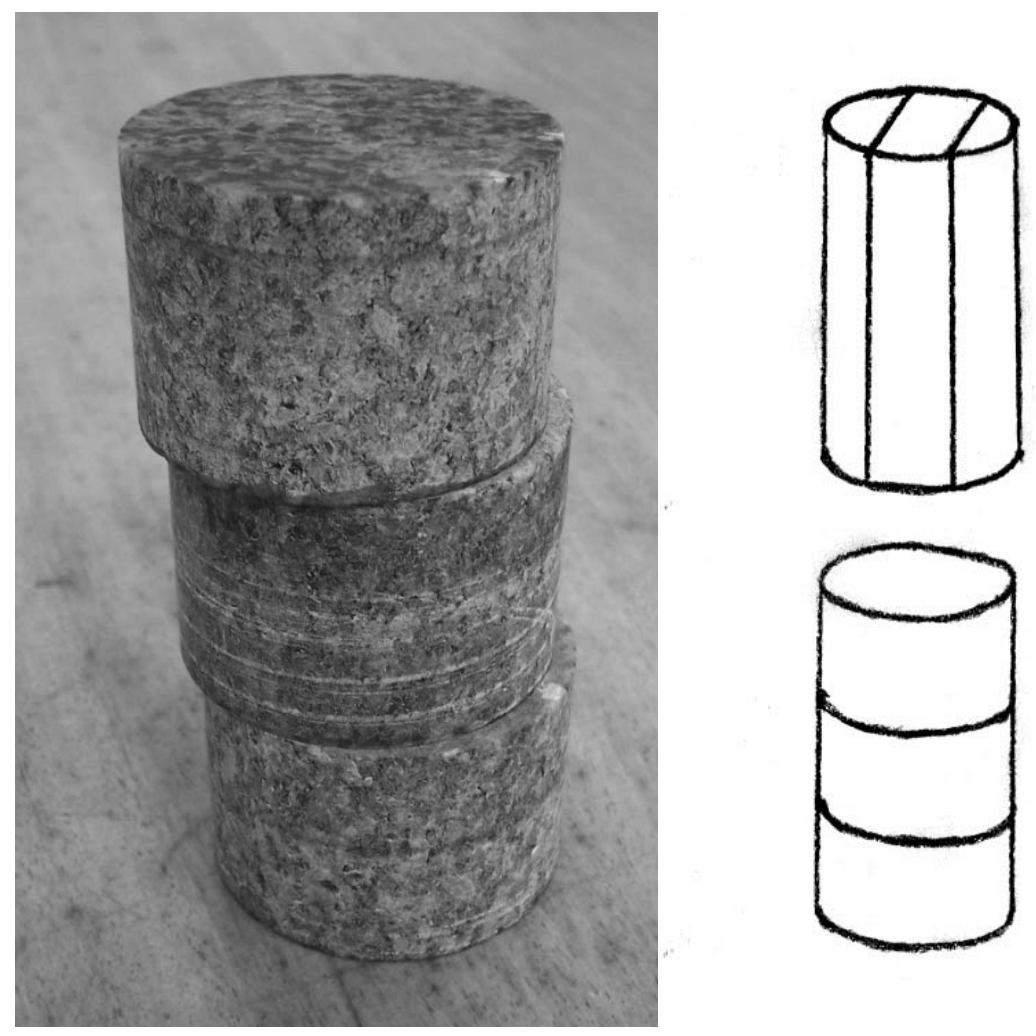

Figure 1 Geometries of the 'fractured' norite specimens

The results of the testing programme are summarised in Table 1, and plotted in the form of the apex points of the Mohr circles in Figure 2. 
Table 1 Summary of laboratory test results

\begin{tabular}{llll}
\hline Test Type & Specimen & $\boldsymbol{\sigma}_{\mathbf{1}} \mathbf{M P a}$ & $\boldsymbol{\sigma}_{\mathbf{3}} \mathbf{M P a}$ \\
\hline UCS & Intact core & 198 & 0 \\
UCS & Intact core & 215 & 0 \\
UCS & Intact core & 191 & 0 \\
Triaxial & Intact core & 271 & 5 \\
Triaxial & Intact core & 322 & 10 \\
Triaxial & Intact core & 380 & 15 \\
Triaxial & Horizontal fractures & 256 & 5 \\
Triaxial & Horizontal fractures & 313 & 10 \\
Triaxial & Horizontal fractures & 372 & 15 \\
Triaxial & Vertical fractures & 278 & 5 \\
Triaxial & Vertical fractures & 333 & 10 \\
Triaxial & Vertical fractures & 359 & 15 \\
UCS & Horizontal fractures & 194 & 0 \\
\hline
\end{tabular}

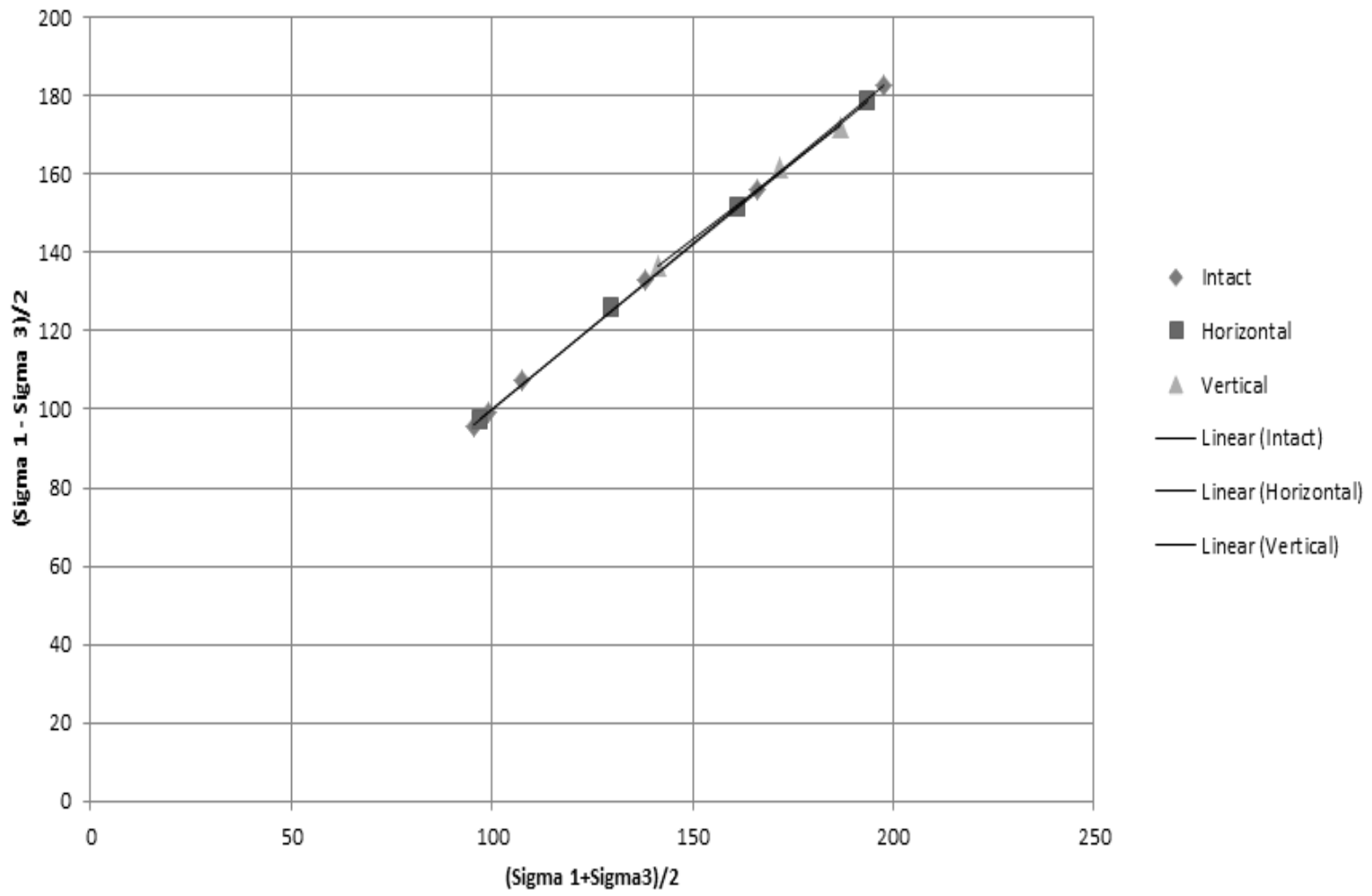

\section{Figure 2 Plot of Mohr circle apex points}

From the results it is quite clear that, under the confined conditions, the presence of the fractures has had no significant influence on the behaviour of the norite. If the results of tests on anisotropic rock loaded at different angles to the foliation direction are considered, as described by Brady and Brown (1993), it could be expected that the effect of the vertical and horizontal fractures would be limited. However, the graphs for 
the intact horizontally fractured and vertically fractured specimens in Figure 2 are effectively coincident. Therefore, it cannot be assumed that the strength of the rock (its $\mathrm{C}$ and $\varphi$ for Mohr-Coulomb, or its m, s, and a for Hoek-Brown) will be reduced by the fracturing. It also cannot be assumed that the rock will be softened (lower modulus of elasticity) by the fracturing.

A century ago, Bridgman (1912) studied the behaviour of materials under very high confining pressures. He found that, in brittle materials, extension fractures could be formed normal to a net compressive stress, and that failure behaviour was often very different from what would be predicted by commonly used criteria. Bridgman's observations are instructive regarding behaviour under confinement and show parallels with the behaviour of the laboratory specimens.

\section{$4 \quad$ Rock mass approach}

If one was to make use of a rock mass classification approach to the effects of preconditioning, it is quite clear that the hydraulic fracturing will affect the rock mass classification value. Additional "joints" will possibly decrease the RQD, thus reducing the Q value (Barton, 2002) and the RMR (Bieniawski, 1989). It will also explicitly reduce the MRMR value in Laubscher's method (Laubscher, 1990), and, in the GSI System (Hoek, 1999), the rock mass will move from a less blocky to a more blocky description, with a corresponding reduction in the GSI value. Rock mass classification numbers have been correlated with rock mass strength (Barton, 2002; Hoek et al., 2002; Laubscher, 1990; Carter et al., 2008) and the implication is that, with a lower rock mass classification value, it could be concluded that preconditioning will therefore reduce the rock mass strength. Further, rock mass classification values have been correlated with rock mass deformation modulus (Barton, 2002; Bieniawski, 1989; Hoek and Diederichs, 2006), and the conclusion from these correlations would be that preconditioning will reduce the modulus of the rock mass. These indications for the rock mass are contrary to the conclusions drawn from the laboratory tests described. There is no reason why, in a confined rock mass situation, preconditioning by hydraulic fracturing should change the confinement conditions (i.e. the in situ stresses), the rock mass strength or the rock mass deformation modulus. Thus the modelling of the preconditioning is not a trivial problem. The perhaps obvious approach of reducing the modulus and softening the rock mass, such as described by Pfitzner et al. (2010), and/or of changing the rock mass strength parameters to reflect a reduced rock mass strength, are probably not correct approaches. They may apparently give results that correspond with observations, but the approaches are flawed because the incorrect mechanisms of behaviour are being modelled - the apparently right answer is being obtained by the wrong method, and this method may not work for prediction of rock mass behaviour in other, new situations.

\section{$5 \quad$ Possible explanations of the beneficial effects of preconditioning by hydraulic fracturing}

It has been shown above that hydraulic fracturing is unlikely to affect rock mass behaviour in its confined condition. However, all mining activities involve removal of rock and hence unloading of the rock mass. The presence of additional fractures will facilitate the unloading process, particularly in a directional sense normal to the planes of the fractures. This would explain the observed more rapid breakthrough that has been achieved in caves after preconditioning. However, the deformation modulus of the rock mass will certainly not be isotropic, and will not be of the same magnitude in loading (increasing stress) and unloading (decreasing stress levels). This therefore represents a problem for "simple" modelling of a preconditioned rock mass by softening the preconditioned zone.

The behaviour of brittle materials in unloading is referred to by Bridgman (1938):

\footnotetext{
"A very beautiful example of rupture on release of pressure and also against the stress is afforded by some recent experiments of D T Griggs [Griggs, 1936]. In these experiments he studied, among other things, the compressive strength of limestone as affected by a hydrostatic pressure, acting over the entire surface of the body, superposed on a compressive load. ... Griggs found in many cases that if the experiment were terminated by release of compressive load and then release of pressure ... the specimen was found, on removal from the apparatus, to be ruptured into discs on planes perpendicular to the original direction of compression. ... The suggestion given by this example prepares us to expect many other examples of rupture on release of a state of stress which
} 
has been preponderantly compressive, but in which there have been sufficiently large differences between different components of stress ...."

The additional fractures in the rock mass resulting from the preconditioning may also result in a lower capacity of the rock mass to store energy, and this will have the effect of allowing energy dissipation at lower stress levels, with consequent lower magnitudes of seismicity. This can certainly be envisaged in the unloading situation that occurs above an undercut and in the cave back. However, below the undercut the unloading effect is more questionable, and it is probable that hydraulic fracturing will have a less beneficial effect in this environment, owing to the continuing, and possibly increasing, condition of confinement.

A further effect is the possible change in the nature of fragmentation of the rock due to the presence of the additional fractures. The laboratory UCS test on the specimen with horizontal fractures, illustrated in Figure 3, demonstrated a somewhat different fragmentation behaviour compared with that usually observed in intact specimens. The central slice of core was extensively fragmented (many smaller fragments, which scattered around the laboratory, are not shown in the photograph), but the two end slices, particularly one of them, were relatively damaged. In contrast, intact specimens of brittle rock after failure usually show very distinct solid cones at each end, with significant fragmentation of the remainder of the core, as illustrated in Figure 4.

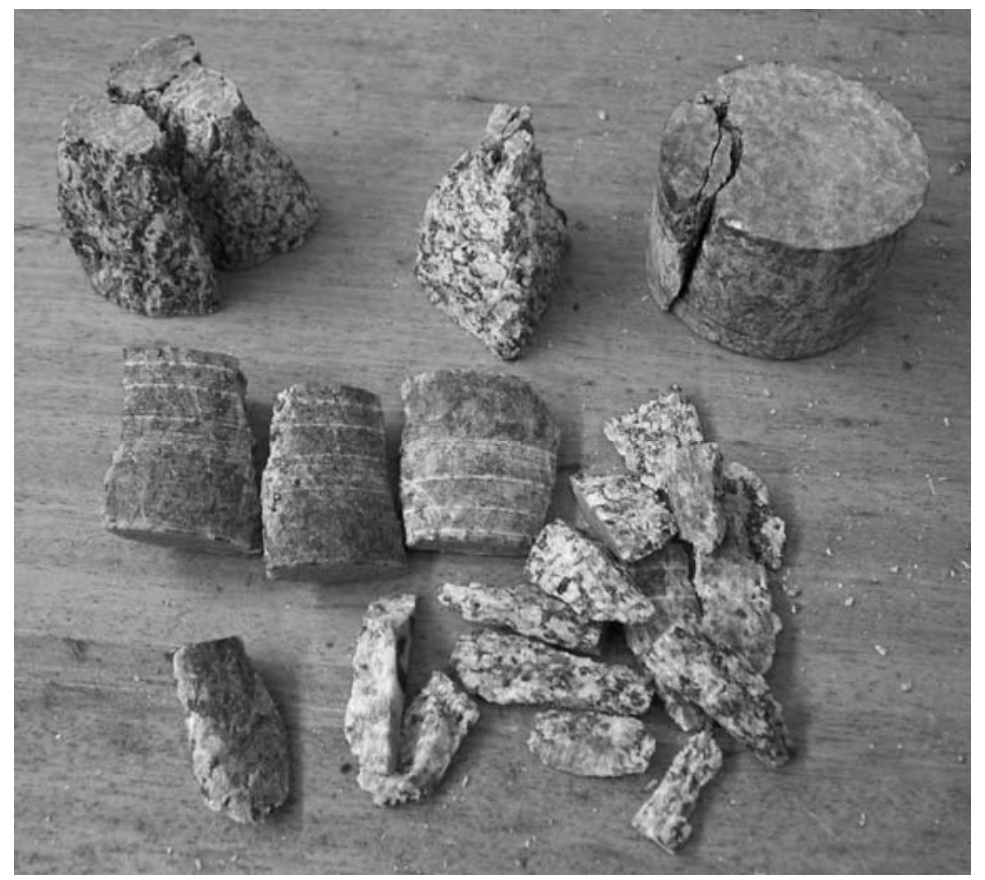

Figure 3 Observed fragmentation of horizontally fractured specimen

If the observations from the laboratory test are valid, then the implication for caving after preconditioning by hydraulic fracturing is that fragmentation from the cave back during mining could be different from that conventionally experienced. Locally there may be intense fragmentation, but adjacent zones in the rock mass might be 'protected', resulting in much coarser fragmentation in those protected zones. It is also to be noted that the hydraulic fractures are orientated normal to the minimum principal stress that was present in the confined rock mass at the time of the hydraulic injection. This orientation might 'interfere' with the process of stress fracturing that would normally develop in the cave back during caving without preconditioning. The presence of continuous surfaces may promote block instability rather than stress-induced instability in the rock mass, changing the fragmentation characteristics. 


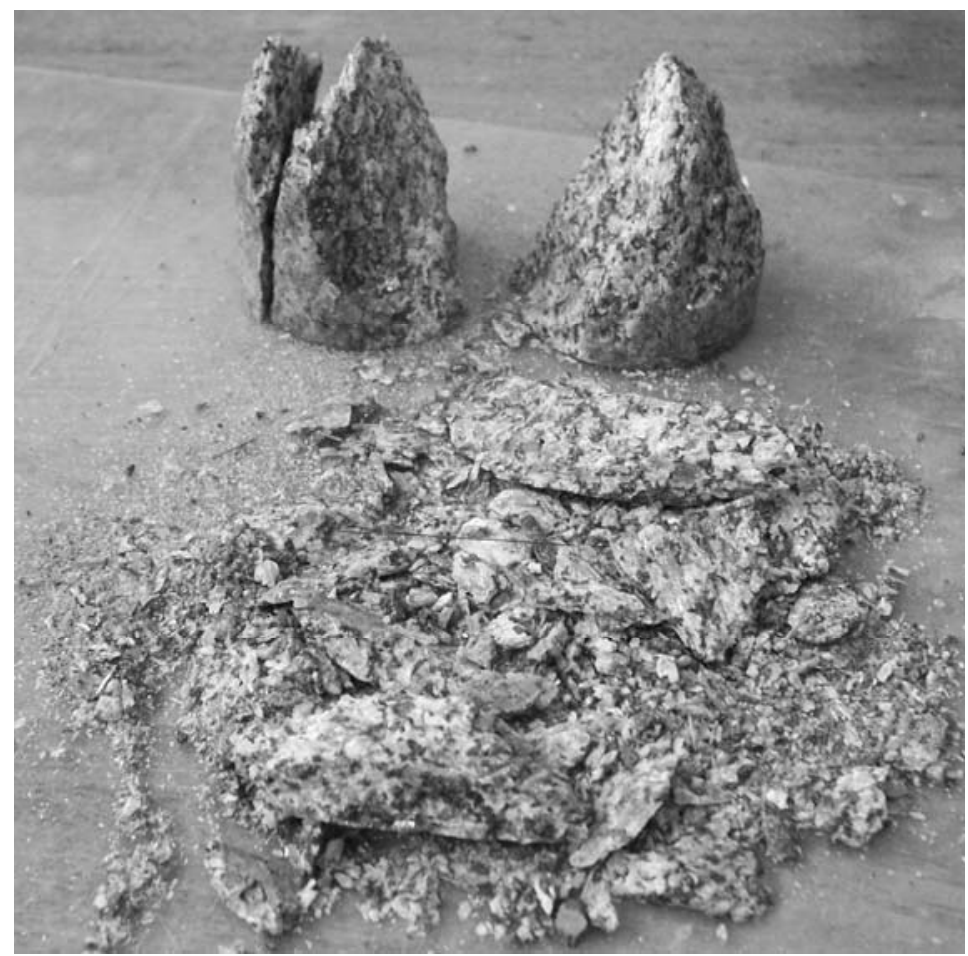

Figure 4 Form of fragmentation usually observed on failure of intact specimens

\section{What are the consequences with regard to numerical modelling of the behaviour of a hydraulically fractured rock mass?}

From the observations above it may be concluded that, to model the behaviour of an hydraulically fractured rock mass realistically, the numerical analysis method must be able to:

- take into account directional variation in strength and deformation characteristics

- take into account the different character of behaviour in loading and unloading

- take into account different failure mechanisms of the rock and rock mass that might occur under different stress conditions, for example, shear failure in a confined situation and extension fracturing in situations in which there is a reduction in confinement in one direction.

It is considered that an approach in which the rock mass behaviour is defined by a single constitutive law (for example, Hoek-Brown; Mohr-Coulomb; strain softening; etc), which is common practice in rock mass modelling, would be inappropriate, since this would not satisfy any of the above requirements. Rather, it appears necessary to explicitly take into account the orientations, spacings and lengths of the induced fractures (and natural joints in the rock mass), so that directionality is accounted for. In addition, alternative fracture criteria should be incorporated so that fracture development can be modelled as it 'would like to develop' (e.g. in shear, tension, compression, or combinations of these), rather than as dictated by some constitutive law. For example, in some areas fractures may initiate in extension, and subsequently extend due to other stress conditions, with rock mass failure finally in shear. In other areas, fractures may initiate in tension, or in shear. The important aspect is that, if the numerical model is to be able to model the behaviour of the hydraulically-fractured rock mass realistically, it should be able to cater for these alternative conditions, both for initiation and for subsequent propagation of rock and rock mass fracture and failure. It would appear that the discrete fracture network approach described by Rogers et al. (2010) and the synthetic rock mass approach referred to by Jeffrey et al. (2010) should be applicable in taking into account the above factors for realistic modelling of the behaviour of a preconditioned rock mass. 


\section{References}

Araneda, O. and Sougarret, A. (2007) Lessons learned in cave mining: El Teniente 1997-2007, in Proceedings First International Symposium on Block and Sub-level Caving, Cape Town, South African Institute of Mining and Metallurgy, pp. 59-71.

Barton, N. (2002) Some new Q-value correlations to assist in site characterization and tunnel design, International Journal of Rock Mechanics and Mining Science, Vol. 39, pp. 185-216.

Bieniawski, Z.T. (1989) Engineering Rock Mass Classification, John Wiley and Sons, New York.

Brady, B.H.G. and Brown, E.T. (1993) Rock Mechanics for Underground Mining, 2nd Edition, Chapman \& Hall.

Bridgman, P.W. (1912) Breaking tests under hydrostatic pressure and conditions of rupture, Philosophical Magazine, Vol. 24, pp. 63-82.

Bridgman, P.W. (1938) Reflections on rupture, Journal of Applied Physics, Vol. 9, pp. 517-528.

Carter, T.G., Diederichs, M.S. and Carvalho, J.L. (2008) Application of modified Hoek-Brown transition relationships for assessing strength and post yield behavior at both ends of the rock competence scale, Journal South African Institute of Mining and Metallurgy, Vol. 108, pp. 325-338.

Hoek, E. (1999) Putting numbers to geology - an engineer's viewpoint, Quarterly Journal of Engineering Geology, Vol. 32, pp. 1-19.

Hoek, E., Carranza-Torres, C.T. and Corkum, B.T. (2002) Hoek-Brown failure criterion, in Proceedings 5th North American Rock Mechanics Symposium, Toronto, University of Toronto Press, pp. 267-274.

Hoek, E. and Diederichs, M.S. (2006) Empirical estimation of rock mass modulus, International Journal of Rock Mechanics and Mining Science, Vol. 43, No. 2, pp. 203-215.

Jeffrey, R.G., Van As, A., Zhang, X., Bunger, A.P. and Chen, Z.R. (2010) Measurement of hydraulic fracture growth in a naturally fractured orebody for application to preconditioning, in Proceedings 2nd International Symposium on Block and Sublevel Caving, Y. Potvin (ed), Australian Centre for Geomechanics, Perth, Australia, pp. 647-662.

Laubscher, D.H. (1990) A geomechanics classification system for the rating of rock mass in mine design, Journal South African Institute of Mining and Metallurgy, Vol. 90, No. 10, pp. 257-273.

Pfitzner, M.J., Westman, E., Morgan, M., Finn, D. and Beck, D. (2010) Estimation of rock mass changes induced by hydraulic fracturing and cave mining by double difference passive tomography, in Proceedings 2nd International Symposium on Block and Sublevel Caving, Y. Potvin (ed), Australian Centre for Geomechanics, Perth, Australia, pp. 677-684.

Rogers, S., Elmo, D. and Webb, G. (2010) Simulating the impacts of hydraulic fracture preconditioning on cavability and fragmentation at the planned Cadia East panel cave, in Proceedings 2nd International Symposium on Block and Sublevel Caving, Y. Potvin (ed), Australian Centre for Geomechanics, Perth, Australia, pp. 663-675.

Van As, A. and Jeffrey, R.G. (2004) Hydraulic fracturing as a cave inducement technique at Northparkes Mine, in Proceedings MassMin 2000, G. Chitombo (ed), 29 October to 2 November 2000, Brisbane, Australia, Australasian Institute of Mining and Metallurgy, Melbourne, pp. 165-172. 
